\title{
Default time from tuberculosis treatment in the southern republic of benin using mixture cure model for survival analysis
}

\begin{abstract}
Background: To date, this is the first statistical analysis of default time from tuberculosis (TB) treatment conducted in the republic of Benin. This cohort study assessed the cured fraction, the conditional probability of default (CPD) from treatment course and identified the risk factors predicting its timing.

Methods: TB case was a patient with positive culture for the Mycobacterium tuberculosis complex or with two sputum smears positive for acid-fast bacilli. The 2008 's cohort of TB patients was extracted from Benin national TB registry. Active TB Patients who were diagnosed between November 2007 and December 2008 were included and followed up to December, $23^{\text {rd }} 2009$ relative to their specific initiation date. Default was defined using the WHO guidelines. Primary endpoint was the time to default from the anti-TB treatment course. Risk factors were assessed with univariate and multivariate Cox regression integrating the mixture cure models.

Results: More than $5 \%(n=64)$ of defaulters were identified with a cured fraction of $94.1 \%$. About $3 \%$ of patients defaulted within the first 2 months (CPD $=0.025$ $\pm 0.004)$. HIV/AIDS co-infection and TB history were independently associated with default time $(\log$-rank $=35.21 ; \mathrm{P}<0.0001$ and log-rank $=10.11 ; \mathrm{P}=0.0015$ respectively). With Cox proportional hazards $(\mathrm{PH})$ analysis, predictors of default time were HIV/AIDS, TB history and Age (hazard ratio [HR] $=3.82[2.28 ; 6.41], \mathrm{P}<$ 0.0001 for HIV-positive, $\mathrm{HR}=0.13$ [0.03; 0.53], $\mathrm{P}=0.0045$ for previous-TB infection and Age $(\mathrm{HR}=3.49[1.25 ; 9.74], \mathrm{P}=0.0170$ for 65 years old or more, respectively) With logistic Cox PH mixture cure model HIV/AIDS and Age significantly increased the probability of default (Odds Ratios $[\mathrm{OR}]=4.04[2.64 ; 7.08], \mathrm{P}<0.0001$ for HIV-positive, and $\mathrm{OR}=4.23[1.58 ; 12.10], \mathrm{P}=0.006$ for 65 years old or more, respectively) whereas TB history significantly reduced default probability $(\mathrm{OR}=0.04$ $[0.004 ; 0.54], \mathrm{P}=0.0148$ for previous-TB infection.

Conclusion: Whatever the alternative model considered, this study provides the first evidence that HIV/AID, TB history and Age were the major predictive factors of default time from anti-TB treatment in Benin. Therefore, additional efforts to improve the compliance of patients with anti-TB treatment through a better management of the co-infection with HIV/AIDS in accordance with patient's specific age group may be an important feature of a prospective TB control strategy in the future. This should be emphasized in the early treatment course for these subgroups of TB patients.
\end{abstract}

Volume 2 Issue 5 - 2015

Tchibozo Anicet Sylvère

Catholic University of Louvain, Belgium

Correspondence: Tchibozo Anicet Sylvère, Catholic University of Louvain, 8A Rue SambrÃ@e 1490 Court-StEtienne, Belgium, Tel: +3247।812997;

Email atchibozo@yahoo.com

Received: April 15, 2015 | Published: April 30, 2015
Abbreviations: AIC, akaike information criterion; ARV, antiretroviral therapy; BIC, bayesian information criterion; CDC, centre for disease control and prevention; CDT, centre of diagnosis treatment; HBCs, high-burden countries; HR, hazard ratio; IUATLD, international union against tuberculosis and lung disease; PTB + smear, positive pulmonary TB; SE, standard error; $\mathrm{TB}$, tuberculosis

\section{Introduction}

\section{Epidemiology of TB worldwide}

Despite the recent progress of global efforts, tuberculosis (TB) remains one of the emergency health problems worldwide. With HIV/ AIDS, it is still the co-leading cause of morbidity and mortality in most of the developing countries. ${ }^{1}$ With $2.5 \%$ of all DALYs, TB was globally responsible for more years of healthy life lost than any other infectious disease in $2006 .^{2}$ Earlier estimations, ranging from 2.0 to $3.0 \%$ of the total, claimed that the disease was the fourth leading specific cause of global DALYs worldwide. ${ }^{3}$ In 2008, 9.4 million incident cases were recorded ${ }^{4}$ or 139 cases per 100000 population after a peak of 143 cases per 100000 in 2004..$^{5}$ In 2007, the prevalence was 135 per 100000 population and a reduction down to 70 per 100000 population was expected. ${ }^{6}$ Additional analyses indicated that the 2008 incident cases included 1.4 million of people living with HIV/AIDS (PLHA). ${ }^{?}$

\section{Epidemiology of TB in benin}

The incidence of all forms of TB was 35 cases per 100000 populations in Benin. ${ }^{8}$ This was slightly different from external estimates which suggested 39 cases per 100000 populations per year. ${ }^{6}$ The incidence has been increasing since 2005 and varied geographically. ${ }^{8}$ The annual risk of infection was $0.8 \%$ for 2008 and TB specifically was responsible for 18 deaths per 100000 populations per year. ${ }^{6}$ The yearly death rate ranged from $6 \%$ to $14 \%$ with a decreasing trend since 2002. HIV/AIDS is an opportunist disease that TB patients have to face. In Benin, the rate of co-infection with HIV/AIDS has fluctuated between $13.0 \%$ and $18.5 \%$ over the 
last five years without being yearly statistically significant. ${ }^{9}$ To fight the disease effectively, Benin set up the so called direct observed treatment short course (DOTS) strategy in the early 1983. Thanks to that, the country reached the objectives of detecting at least $70 \%$ of TB patients and to successfully treat at least $85 \%$ of cases detected. ${ }^{10}$ In order to sustain this achievement, TB patients have to fully comply with the anti-TB- treatment. By doing so, will help to half or possibly more by 2015 the global burden of TB relative to its 1990 level as planned for the United Nation Millennium Development Goals. ${ }^{4}$ Treatment failure is, therefore, an unaffordable outcome for patients and represents an important challenge for national TB programs (NTPs). It turns out that, inadequate adherence to treatment is an important factor of death and emergence of MDR TB. ${ }^{11,12}$ Currently, patients can be easily cured through a short-term chemotherapy. Nevertheless, the disease remains extremely threatening despite the existence of cost-effective treatments that can cure more than $95 \%$ of patients. ${ }^{13}$

\section{The problem}

Up to two million individuals die from TB each year worldwide. A reason of this is the percentage of patients who unfortunately interrupt the treatment course ${ }^{14}$ and poor compliance with treatment is a real problem for NTPs. ${ }^{15,16}$ In order for the treatment to be effective, patients must take their treatment exactly as prescribed for the full amount of time according their baseline characteristics. Hence, TB surveillance through the DOTS strategy seems insufficient to reverse the epidemic trend of the disease. ${ }^{17,18}$ It turns out that patient's compliance is a key factor in meeting treatment success and thereby in reducing the burden of TB. But in resource-constrained countries such as Benin where health care services are not well developed, delayed presentation for treatment and interruption of treatment are the two major challenges for NTPs. ${ }^{19}$

\section{Level of treatment interruption}

High rates of default are a common problem, with a median value of $17 \%$ Worldwide ${ }^{20}$ A review of adherence to TB therapy found a treatment interruption rate of $20 \% .{ }^{21}$ More recent estimates of default rates in DOTS programs have suggested a range from $6 \%$ to $30 \%{ }^{16}$ In the USA as well as in Brazil, treatment interruption was estimated to $25 \%$. In China, a study reported a proportion of $12.2 \%$ in treatment interruption. ${ }^{22}$ In Russia, treatment interruptions were common with $63 \%$ of defaulters..$^{23}$ Closer to Benin in Africa, a $14.4 \%$ of default emerged from a study conducted in Nigeria. ${ }^{24} \mathrm{~A}$ research from Southern Ethiopia revealed $20 \%$ of default. ${ }^{25}$ In South Africa, one of the top five countries with the largest number of cases ${ }^{4}$ $17 \%$ of defaulters were pointed out. ${ }^{17}$ In Benin, interruption of TB treatment issues has remained undocumented to date. Of course a report suggested that the proportion of default fell from $11 \%$ in 2002 to $3 \%$ in $2005 .{ }^{9}$ But this report did not address the risk factors and the timing of the problem.

\section{Risk factors}

A significant proportion of patients stop treatment before completion for various reasons. While the drug supply chain plays a major role, ${ }^{11}$ gender, alcoholism, treatment after default, HVI/ AIDS, socioeconomic status, the stigma of the disease, the lack of information, dissatisfaction with the treatment and its delivery, and inaccessibility of treatment ${ }^{17,26-35}$ were found as predicting the treatment interruption. The standard anti-tuberculosis therapy consists of a cocktail of drugs taken over a period of at least 6 months for new patients and 8 months for patients under retreatment. Because of the long duration of the therapy, there is a risk of treatment interruption or default, a phenomenon that contributes to prolonged infectiousness, drug resistance, relapse and death. ${ }^{1,36}$ Treatment regimens are associated with significant side-effects such as hepatitis, dyspepsia, which were responsible for termination of therapy in up to $23 \%$ of patients during the intensive phase. ${ }^{37}$

\section{Consequence of treatment interruption}

Whatever the cause however, default from treatment is a problem for patients, their families, those who care for them, and those responsible for TB program. ${ }^{38}$ Breaking off treatment half-way or earlier is the worst thing one can do as the disease will very likely recur and not entirely cured cases add more infected cases. ${ }^{31}$ The public health and clinical consequences of TB treatment interruption are severe. Default is responsible for the increasing of the cost of treatment and almost invariably leads to relapse and death. ${ }^{39}$ Compared with those who fully comply with treatment, defaulters may constitute stocks of TB disease perpetuation and have high post-treatment mortality and rates of recurrent disease. ${ }^{40,41}$

\section{Timing of default from treatment}

Evidence has shown that failure time is a right censored data. ${ }^{42,43}$ Accordingly, the specific time when anti-TB treatment is interrupted relative to its initiation date needs a close consideration. A systematic review showed that a substantial proportion of defaulters leave the treatment course in the later stages. ${ }^{44}$ However, previous studies claiming earlier occurrence of default, pointed to treatment interruption occurring mainly around the second month, with a median time off anti-TB treatment of 4 weeks. ${ }^{45}$ In settings with poor TB care system, the first 2 months of the anti-TB treatment correspond to the cut off time used to decide whether a patient defaults or not. In addition, the first two months also correspond to the duration of the intensive phase of the treatment regimen applied to new patients. ${ }^{46}$

\section{Objectives}

Facts proved that health improvement occurs not only through improved socioeconomic development, but also through deliberate, rational attempts to reduce the burden of diseases by the application of scientific knowledge and technology. ${ }^{47}$ Accordingly, the primary objectives of this study were:

a) To evaluate the proportion of default from anti-TB treatment at the centers of diagnosis and treatment (CDT) of Atltantique and Oumé Plateau in the Republic ofBenin

b) To evaluate the proportion of immune or cured patients in the 2008 cohort of TB patients

c) To evaluate the conditional probability that a patient has interrupted the anti-TB treatment within the first 2 months relative to the initiation date and its corresponding hazard rate

d) To determine factors mainly predicting the default time from anti-TB treatment

e) To analyze the risk pattern of treatment interruption with respect to patient's demographic and clinical characteristics.

\section{Methods}

\section{The setting}

Located in West Africa in the Gulf of Guinea, Benin is made up of 12 provinces and 77 local subdivisions (Figure 1). In 2008, the 
country was populated of 8414801 million $^{48}$ with an annual growth rate of $3.25 \% .{ }^{49}$ The population was rather young with $49 \%$ of people younger than 15 years old. Mean reproduction rate was 5.7 children and human development index (HDI) was 0.437 , classifying Benin at the $163^{\text {rd }}$ rank out of a total of 177 countries. The rate of poor households was estimated to $52.2 \%$. Around $77 \%$ of the population lived at less than $5 \mathrm{~km}$ from a health unit, with a low frequenting rate of $44 \%$. Health financing is mostly provided by households up to $52 \%$.

\section{Diagnosis and treatment of tuberculosis}

Since 1983, Benin's policy against TB was based on the combination of case-finding and chemotherapy treatment in accordance with DOTS strategy. The principle consists in analyzing the suspects' sputum smears tracking the presence of mycobacterium tuberculosis. Whenever the mycobacterium test was positive, patients were automatically assigned a specific treatment in the CDT their living place refers to. TB treatment was provided totally free of charge as recommended by the WHO. ${ }^{14}$

\section{Design and study population}

This was an observational study and lists of cases were obtained by querying the national TB register using International Standards for Tuberculosis Care (ISTC) forms (Appendix 1).

Target data were all active TB patients registered for DOTS at the CDT of Porto-Novo (CPP Akron) and Cotonou (CNHPP) in the south of Benin from November 2007 to December 2008. These two $\mathrm{CDT}$ are situated in the provinces of Ouémé-Plateau and AtlantiqueLittoral in the south of Benin and pooled 38.21\% (8 414 801/3 515 255) of the total population. ${ }^{8}$

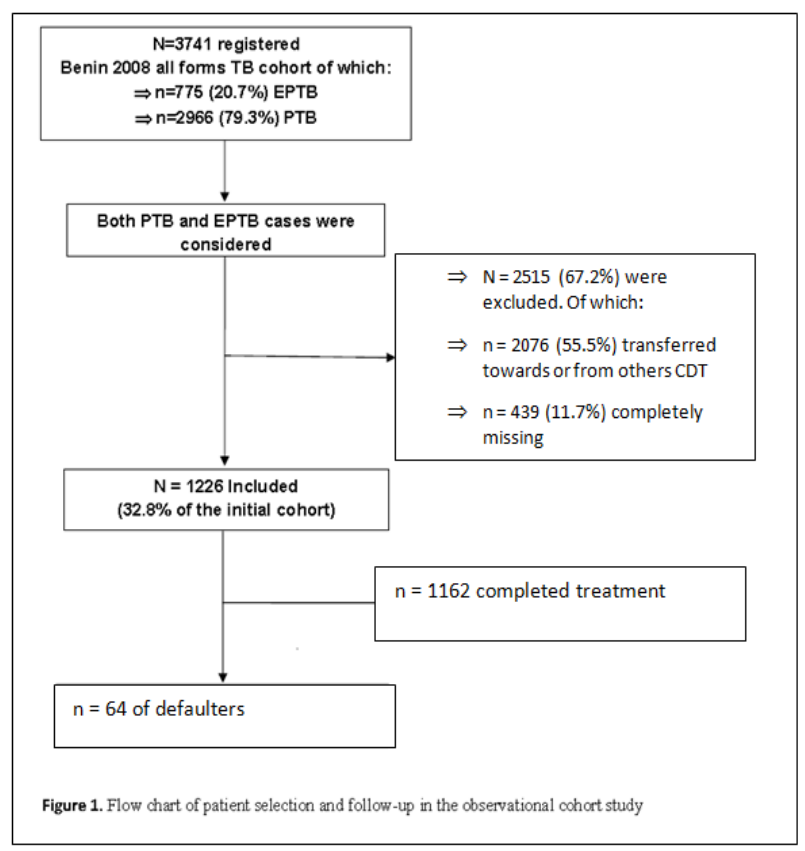

Thus the cohort of interest was a fraction of the country level 2008 cohort of TB patients identified in all the 55 CDT of Benin during the same period. Put together, These 55 CDT combined 3741 of all forms of active TB cases diagnosed in the whole country.

\section{Definitions}

\section{TB Case}

TB Case was a patient in whom TB has been bacteriologically confirmed or diagnosed by a clinician. ${ }^{38}$ TB history and treatment outcomes were classified using the standard World health organization (WHO) definitions $38 .{ }^{50}$ As with HIV/AIDS treatment, TB therapy requires high $(>90 \%)$ compliance to facilitate cure 50 . TB history was divided into new, treatment after relapse, treatment after failure, treatment after default or transfer in. Final TB treatment outcome was one of the following: successful, failure, death, default and transferred out. A successful treatment outcome included "cured" or "completed".

\section{The end point}

Default time was the end point. Default was defined using the WHO guidelines for TB surveillance strategy. Accordingly, a defaulter was a patient whose treatment was interrupted for 2 consecutive months or more. Thus, Default status was coded 1 if a given TB patient defaulted and 0 if a TB patient treatment outcome was set to "Died" "Treatment success" or "Not evaluated". The follow-up time was the time span in month between the treatment initiation date and the date the treatment final outcome was evaluated. Treatment initiation date was between December 2007 and 2008 when each patient started the anti-TB therapy after diagnosis.

\section{The cured fraction of the cohort}

Immune patients were those who would have never experienced default from anti-TB treatment provided that there has been sufficient follow up to observe them. The rational of the cured fraction was that the 2008 cohort of patients pooled both susceptible (uncured) to default individuals and non-susceptible (cured) to default individuals. Mixture cure models are adequate for such kind of data. Interest was to estimate simultaneously whether default has occurred and when it has occurred given that it could have occurred..$^{51}$ Interest was also in how covariates have influenced the cured fraction and how they were related to default time.

\section{The conditional probability of default within the first 2 months}

It is the estimate of the probability that a default will occur within the first 2 months, given that no default has yet occurred. ${ }^{43,52}$ That is the hazard rate or the intensity of default within this time interval.

\section{Data quality management and Statistical Analysis Plan}

SAS software, version 9.2 (SAS Institute Inc., Cary, NC, USA) was used for data extraction, data integration and for statistical analysis. Categorical variables such as ARV (yes, no) and CTM (yes, no) were excluded from the modeling due to a huge percentage of missed observations. For the variables retained, missing values were replaced using multiple imputations. The variable age was converted into a qualitative variable using categories children (014 years), active (15-64 years) and old (65 years or over) as cutoff points. Survival analysis (Cox PH model) techniques was applied for modeling default time. ${ }^{42,43}$ Proportions of default across strata of patients' characteristics were calculated. Differences between subcategories were compared using the chi-square statistic and Fisher's exact test was used if expected value of a cell was less than 5 . The cured fraction was computed by summing the simulated individual posterior probability of being cured. ${ }^{51}$ This was done 
through SAS means procedure. In univariate analysis, default time was analyzed with the Kaplan-Meier estimator (KME) $)^{43,53,54}$ and the log-rank test was applied to compare the default time function between subcategories. The life table method was used to compute the conditional probability of default within the first 2 months. The life table method was preferred because: first, the sample size was large (1226) and second, default time, precisely measured, was grouped into intervals with a lag of 2 months. ${ }^{53}$ In the multivariate analysis, two models were considered to adjust for covariates with $p$-value $\leq$ 0.20 from the univariate analysis. ${ }^{55}$

First, the standard Cox regression was fitted under the $\mathrm{PH}$ assumption. That is:

$h\left(t ; X_{1}, X_{2}, \ldots, X_{k}\right)=\lambda_{0}(t) \exp \left(\lambda_{1} X_{1}+\lambda_{2} X_{2}+\ldots+\lambda_{k} X_{k}\right)$. Where $\lambda_{0}(\mathrm{t})$ is the baseline hazard of default at time $\mathrm{t}$ and $\mathrm{x} 1$, xk are the $\mathrm{k}$ independent covariates. Here, $\mathrm{t}$ is the time to default. This was implemented in SAS using the PHREG procedure. ${ }^{53}$ Second, the logistic Cox PH mixture cure model was used to account for the cure fraction of the sample. It assumes a binary distribution to model the incidence probability and a parametric failure time distribution to model the latency. Kuk and $\mathrm{Chen}^{56}$ extended the model by using Cox proportional hazards regression for the latency. That is:

$$
S(t, x, z)=\pi(z) S(t \mid U 1, x)+(1-\pi(\mathrm{z})) .
$$

Where $S(t \mid x, z)$ is the conditional survival function for the entire cohort. $\mathrm{S}(\mathrm{t} \mid \mathrm{U}=1, \mathrm{x})=\mathrm{P}(\mathrm{T}>\mathrm{t} \mid \mathrm{U}=1, \mathrm{x})$ is the survival function for susceptible individuals given a covariate vector $\mathrm{X}=(\mathrm{x} 1, \ldots, \mathrm{xk})^{\prime}$ and $\pi(\mathrm{z})=\mathrm{P}(\mathrm{U}=1 \mid \mathrm{z})$ is the probability of being susceptible given a covariate vector $Z=(z 1, \ldots, z p)$ ' which may include the same covariates as $x$. These were implemented through the PSPMCM SAS ${ }^{\circledR}$ macro. ${ }^{57}$ Default time can take the form of parametric distributions such as Weibull and log-logistic which are commonly used to model survival data. ${ }^{58}$ Estimates were computed using the SAS NLMIXED procedure for the parametric component and through the
Expectation Maximization (EM) algorithm for the Cox PH mixture cure component. ${ }^{59}$ Four models were proposed and the best one was selected based on the goodness of fit statistics: Deviance $(-2 \log L)$, AIC, AICC and BIC criteria. That is the model with the smallest criteria. For all the analyses conducted, a p-value of 0.05 was defined as statistically significant.

\section{Ethical consideration}

The Good Epidemiological Practice (GEP) was followed. ${ }^{60}$ This way, TB patients were identified anonymously through a unique identification number in the database. In addition, the main objectives and reasons for this study have been explained in detail to the Benin PNT Board who gave its approval.

\section{Results}

\section{Study population: Selection and characteristics}

A total of 1226 all forms of TB patients were successfully retained (Figure 1), representing $33 \%$ of the 3741 of TB patients who initiated the anti-TB treatment in the whole country in 2008. Among those, $84.2 \%$ were Beninese, $15.3 \%$ were Nigerian and $0.6 \%$ did not have a clearly defined citizenship. They were mainly male $(65 \%)$. Median age was $31^{25,40}$ years. Most of them $(94.1 \%)$ were aged between 15 years and 64 years. According to the default status, patients had similar demographic characteristics and differed only for clinical characteristics, including co- infection with HIV/AIDS, TB history and marginally for CDT and the regimen undergone (Table 1). On December, $23^{\text {rd }} 2009$ when the last treatment final result has been delivered, the maximum default time was 12 months with a median of $6^{6,7}$ months. At that cut-off date, a total of $64(5.22 \%)$ patients defaulted from the anti-TB treatment, $94.78 \%$ of patients completed the treatment as planned by the treatment protocol and the simulated cured fraction was $94.10 \%$ (Table 2 ).

Table I Baseline characteristics of TB patients (\%) by Default status, south of Benin, cohort 2008

\begin{tabular}{|c|c|c|c|c|c|}
\hline \multirow{2}{*}{ Factors of Risk - no/N (\%) } & \multirow{2}{*}{$\begin{array}{l}N \\
1226\end{array}$} & \multicolumn{2}{|l|}{ Default } & \multirow{2}{*}{ Chi-Square } & \multirow{2}{*}{ P-Value } \\
\hline & & Yes $(N=64)$ & No $(N=1 \mid 62)$ & & \\
\hline Age group - no/N (\%) & & & & 4.09 & 0.1332 \\
\hline $0-14$ & $4 I$ & $\mathrm{I}(0.08)$ & $40(3.26)$ & & \\
\hline $15-64$ & 1153 & $59(4.8 I)$ & 1094(89.23) & & \\
\hline $65+$ & 32 & $4(0.33)$ & $28(2.28)$ & & \\
\hline Gender - no/N. (\%) & & & & 1.4 & 0.2819 \\
\hline Male & 797 & $46(3.75)$ & $75 I(6 I .26)$ & & \\
\hline Female & 429 & $18(1.47)$ & $4 \mathrm{II}(33.52)$ & & \\
\hline Nationality - no/N (\%) & & & & 0.996 & 0.6393 \\
\hline Benin & 1032 & $52(81.25)$ & $980(79.93)$ & & \\
\hline Nigeria & 187 & $12(18.75)$ & $175(\mid 4.27)$ & & \\
\hline Other & 7 & $0(0.00)$ & $7(0.57)$ & & \\
\hline Bacilloscopy before treatment & & & & 2.04 & 0.3602 \\
\hline Negative & 115 & $9(0.73)$ & $106(8.65)$ & & \\
\hline Positive & 1029 & $52(4.24)$ & $977(84.04)$ & & \\
\hline Unknown & 182 & $3(0.24)$ & $79(6.44)$ & & \\
\hline
\end{tabular}


Table Continued

\begin{tabular}{|c|c|c|c|c|c|}
\hline \multirow{2}{*}{ Factors of Risk - no/N (\%) } & \multirow{2}{*}{$\begin{array}{l}N \\
\text { I } 226\end{array}$} & \multicolumn{2}{|l|}{ Default } & \multirow{2}{*}{ Chi-Square } & \multirow{2}{*}{ P-Value } \\
\hline & & Yes $(N=64)$ & No $(N=1162)$ & & \\
\hline TB History - no/N (\%) & & & & 13.52 & 0.001 \\
\hline New & & $52(4.24)$ & $1077(87.85)$ & & \\
\hline Other & & $12(0.98)$ & $85(6.93)$ & & \\
\hline Form of TB - no/N (\%) & & & & 0.35 & 0.7934 \\
\hline PTB & 1147 & $6 \mathrm{I}(4.98)$ & $1086(88.58)$ & & \\
\hline EPTB & 79 & $3(0.24)$ & $76(6.20)$ & & \\
\hline HIV - no/N (\%) & & & & 34.96 & $<0.0001$ \\
\hline Positive & 233 & $30(2.45)$ & $203(16.56)$ & & \\
\hline Negative & 966 & $32(2.61)$ & $934(76.18)$ & & \\
\hline Unknown & 27 & $2(0.16)$ & $25(2.04)$ & & \\
\hline Regimen - no/N (\%) & & & & 5.54 & 0.0605 \\
\hline ERHZR & 1111 & $53(4.32)$ & $1058(86.30)$ & & \\
\hline SERHZ & 97 & $10(0.82)$ & $87(7.10)$ & & \\
\hline $\mathrm{RHZ}$ & 18 & $I(0.08)$ & I7(1.39) & & \\
\hline Unite (DOT) - no/N (\%) & & & & 5.27 & 0.0571 \\
\hline CNHPP & 593 & $37(3.02)$ & $556(45.35)$ & & \\
\hline CHPPIAKRON & 384 & $2 I(I .7 I)$ & $363(29.61)$ & & \\
\hline Other & 249 & $6(0.49)$ & $243(19.82)$ & & \\
\hline
\end{tabular}

Table 2 Distribution of default time, the proportion of default and the cured fraction

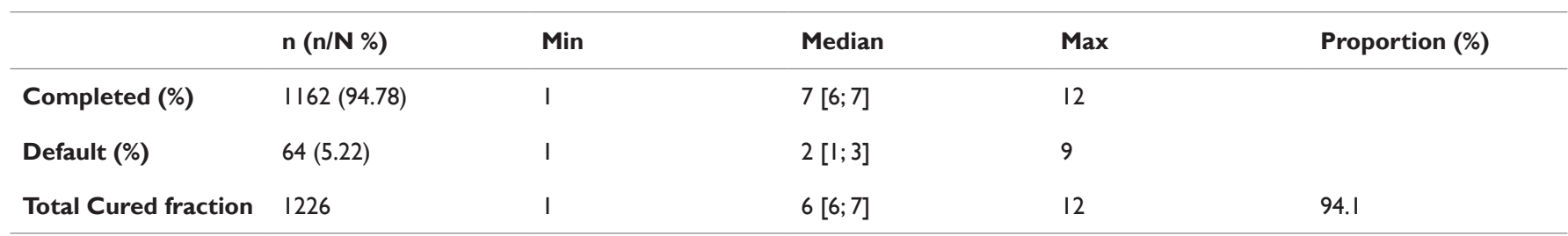

Risk of default from TB treatment within the first 2 months

The conditional probability that a patient has defaulted within the first 2 months was estimated to $1.25 \pm 0.004$ (Table 3 ). The corresponding mid-point hazard rate was $0.013 \pm 0.002$. The probability of passing 2 months without anti-TB treatment interruption was $0.975 \pm 0.004$. The hazard function has declined linearly from the treatment starting date up to the seventh month. After that, it was no more linear as an increased departure was noted from the seventh month (figure 2). From the eighth month up to the end, one default occurred, which induced the change observed in the global pattern of the hazard function. More than $95 \%(63 / 64)$ of total defaults had happened within the first seven month with almost $47 \%$ (30/64) occurring within the first 2 months which corresponds to the intensive phase of the anti-TB chemotherapy.

Table 3 Conditional probability of default (CPD) from anti-TB treatment within the first 2 months

\begin{tabular}{|c|c|c|c|c|c|c|}
\hline Time & Failed & Censored & Sample Size & $C P D \pm S E$ & Survival \pm SE & Midpt Hazard \pm SE \\
\hline $0-2$ & 30 & 6 & 1223.0 & $0.025 \pm 0.004$ & I & $0.013 \pm 0.002$ \\
\hline $2-6$ & 31 & 67 & 1156.5 & $0.027 \pm 0.005$ & $0.975 \pm 0.004$ & $0.012 \pm 0.002$ \\
\hline $6-8$ & 2 & 922 & 631.0 & $0.003 \pm 0.002$ & $0.949 \pm 0.006$ & $0.002 \pm 0.001$ \\
\hline $8-12$ & I & 156 & 90.0 & $0.011 \pm 0.001$ & $0.946 \pm 0.007$ & $0.003 \pm 0.003$ \\
\hline $12-$. & 0 & II & 5.5 & 0 & $0.936 \pm 0.012$ & \\
\hline
\end{tabular}




\section{Risk factors predicting default time from anti-TB treatment}

To identify the risk factors of default and its timing, covariates listed in table 4 were included in both univariate and multivariate of survival and mixture cure analyses.

\section{Univariate analysis of default time}

Besides, the unit of health where patients were followed-up, under the DOT strategy and the effects of regimen underwent, were more marginal $(\log$-rank $=5.20, \mathrm{P}=0.0744$ and log-Rank $=4.99, \mathrm{P}=$ 0.0823 respectively). The other covariates were apparently unrelated to default and its timing (Table 4).

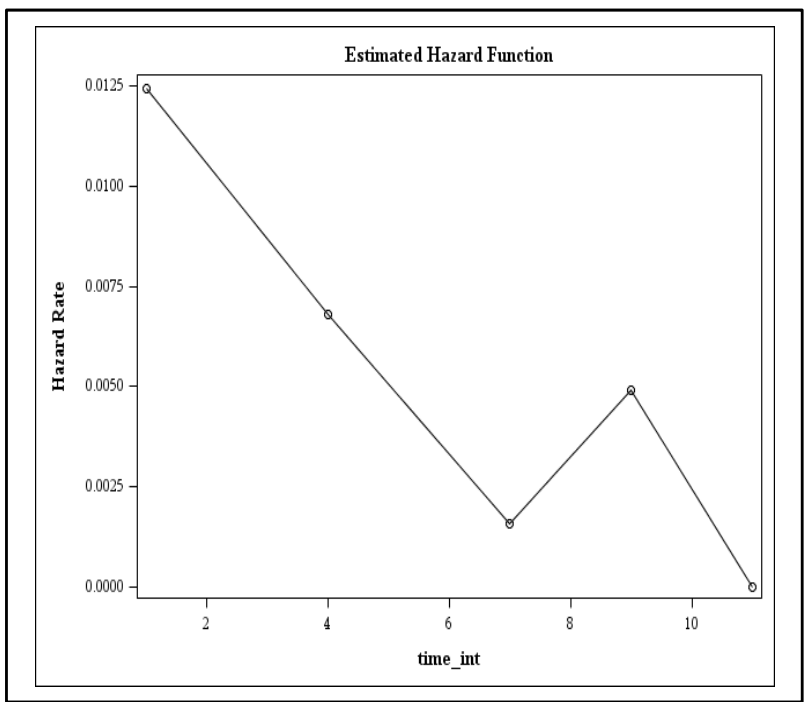

Figure 2 Hazard functions of the default time from anti-TB treatment

\section{Multivariate analysis of default time using the Cox's PH model}

For the classical Cox' $\mathrm{PH}$ analysis, covariates included were those with $p$-value less than or equal to 1.2. When adjusted for all these potential risk factors at hand, HIV/AIDS (HIV+/HIV-), TB history (other/new) and age (65 years old or more/15-64 years old) were the risk factors predicting default time from anti-TB treatment (Table 5). $\mathrm{HR}$ and $95 \% \mathrm{CI}$ were 3.82 [2.28; 6.41], 0.13 [0.03;0.53] and 3.49 $[1.25 ; 9.74]$ respectively. The effects of regimens (SEHRZ/ERHZ) remained marginal. No time dependent covariates led to a statistically significant HR since all the corresponding 95\%CI included 1. Moreover, the linearity hypothesis was not rejected (Table 6). Thus the proportional hazards assumption was satisfied.

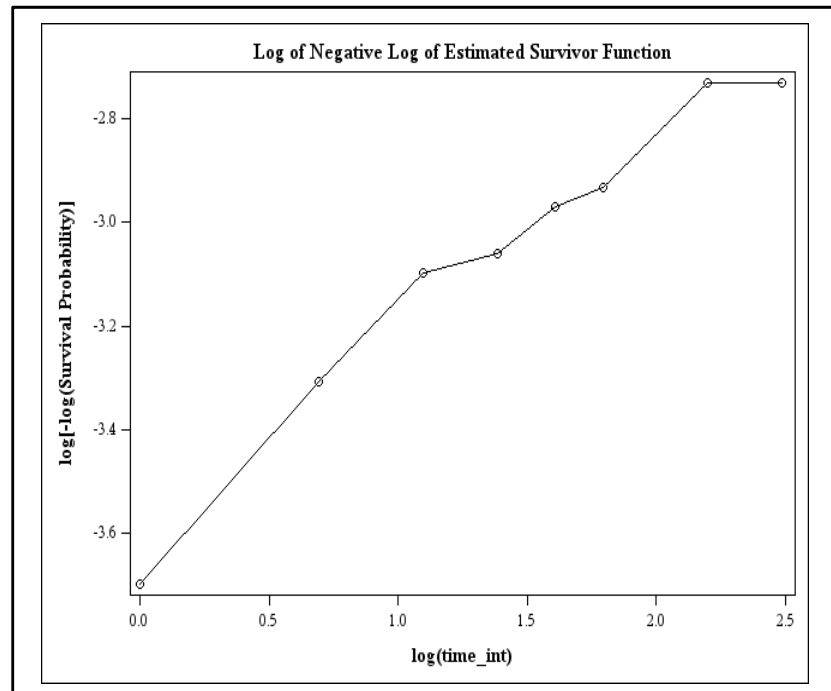

Table 4 Independent association between default time and the characteristics of patients

\begin{tabular}{|c|c|c|c|c|}
\hline \multirow{2}{*}{ Factors of Risk - no/N (\%) } & \multicolumn{2}{|l|}{ Default } & \multicolumn{2}{|l|}{ Log-rank } \\
\hline & Yes $(\mathbf{N}=64)$ & No $(N=|| 62)$ & Chi-square & P-value \\
\hline Age group - no/N (\%) & & & $4.4 I$ & 0.1102 \\
\hline $0-14$ & I (0.08) & $40(3.26)$ & & \\
\hline $15-64$ & $59(4.8 \mathrm{I})$ & $1094(89.23)$ & & \\
\hline $65+$ & $4(0.33)$ & $28(2.28)$ & & \\
\hline \multicolumn{5}{|l|}{ Gender } \\
\hline Male & $46(3.75)$ & $751(61.26)$ & 1.38 & 0.24 \\
\hline Female & $18(1.47)$ & $411(33.52)$ & & \\
\hline Nationality - no/N (\%) & & & 0.99 & 0.6086 \\
\hline Benin & $52(81.25)$ & $980(79.93)$ & & \\
\hline Nigeria $(n=\mid 87)$ & $12(I 8.75)$ & 175 (14.27) & & \\
\hline Other $(n=7)$ & 0 & $7(0.57)$ & & \\
\hline Bacilloscopy prior treatment - no/N (\%) & & & 2.19 & 0.3352 \\
\hline Negative $(n=\mid 15)$ & $9(0.73)$ & $106(8.65)$ & & \\
\hline Positive $(n=1029)$ & $52(4.24)$ & $977(84.04)$ & & \\
\hline Unknown (n=|82) & $3(0.24)$ & $79(6.44)$ & & \\
\hline
\end{tabular}


Table Continued

\begin{tabular}{|c|c|c|c|c|}
\hline \multirow{2}{*}{ Factors of risk - no/N (\%) } & \multicolumn{2}{|l|}{ Default } & \multicolumn{2}{|l|}{ Log-rank } \\
\hline & Yes $(\mathrm{N}=64)$ & No $(N=|| 62)$ & Chi-square & P-value \\
\hline Bacilloscopy at 2 months - no/N (\%) & & & 0.54 & 0.7634 \\
\hline Negative & $12(1.05)$ & $890(78.00)$ & & \\
\hline Positive & $40(3.5 I)$ & $120(10.52)$ & & \\
\hline Other & $3(0.26)$ & $76(6.66)$ & & \\
\hline TB History - no/N (\%) & & & 10.11 & 0.0015 \\
\hline New & $52(4.24)$ & $1077(87.85)$ & & \\
\hline Other & $12(0.98)$ & $85(6.93)$ & & \\
\hline Form of TB - no/N (\%) & & & 0.34 & 0.5593 \\
\hline Pulmonary & $61(4.98)$ & $1086(88.58)$ & & \\
\hline Extra-pulmonary & $3(0.24)$ & $76(6.20)$ & & \\
\hline \multicolumn{5}{|l|}{ HIVIAIDS } \\
\hline Positive & $30(2.45)$ & $203(16.56)$ & 35.21 & $<0.0001$ \\
\hline Negative & $32(2.6 \mathrm{I})$ & $934(76.18)$ & & \\
\hline Unknown & $2(0.16)$ & $25(2.04)$ & & \\
\hline Regimen - no/N (\%) & & & 4.99 & 0.0823 \\
\hline ERHZR & $53(4.32)$ & $1058(86.30)$ & & \\
\hline SERHZ & $10(0.82)$ & $87(7.10)$ & & \\
\hline $\mathrm{RHZ}$ & I $(0.08)$ & $17(1.39)$ & & \\
\hline Unit (DOT) - no/N (\%) & & & 5.2 & 0.0744 \\
\hline Cotonou & $37(3.02)$ & $556(45.35)$ & & \\
\hline Porto-Novo/Akron & $21(1.7 I)$ & $363(29.6 I)$ & & \\
\hline Other & $6(0.49)$ & 243 (19.82) & & \\
\hline
\end{tabular}

The univariate survival analysis pointed out that the co-infection with HIVIAIDS and TB history were highly significantly associated with default time of ant-TB treatment (log-rank $=35.21, \mathrm{P}<0.000 \mathrm{I}$ for HIV/AID positive and log-rank $=10.1 \mathrm{I}, \mathrm{P}=0.0015$ for TB history respectively).

Table 5 Factors predicting default time: Cox Regression and $\mathrm{PH}$ assumption

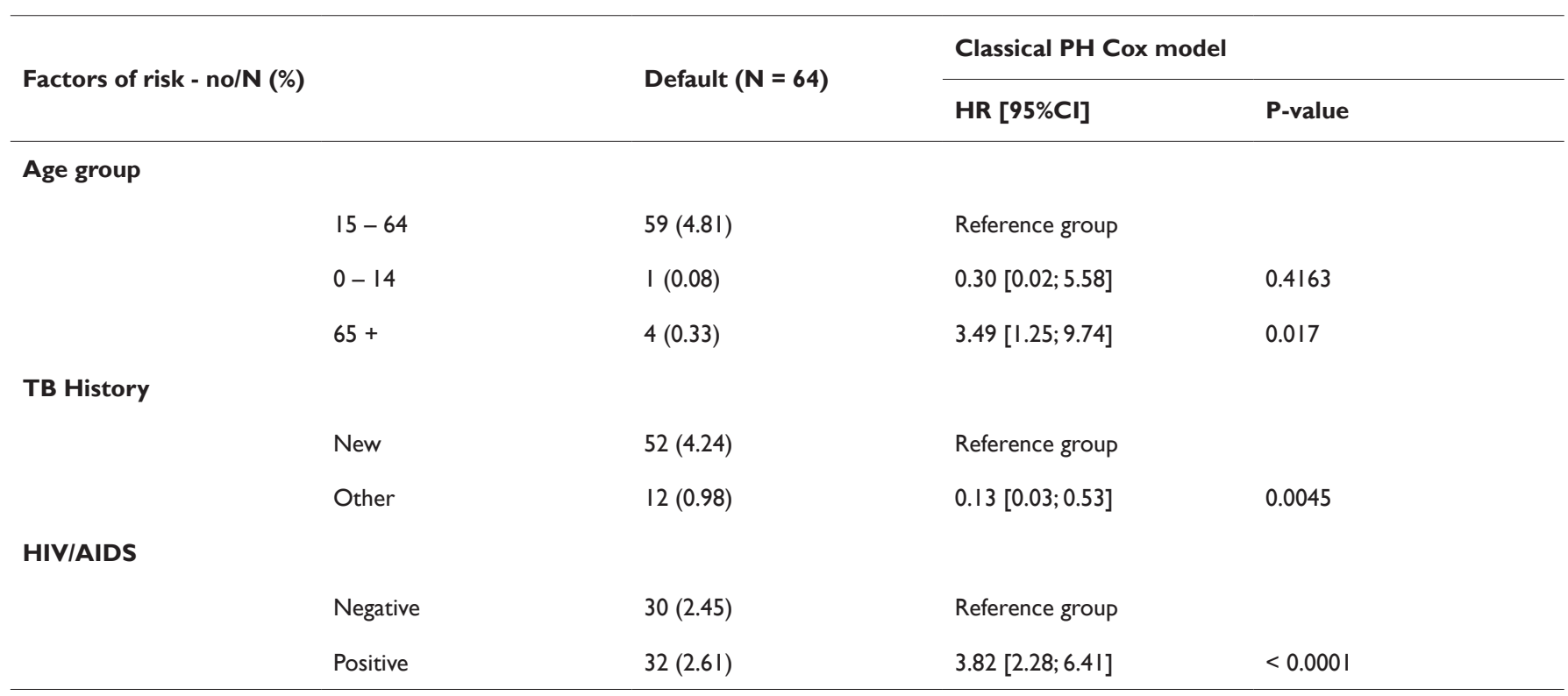


Table Continued

\begin{tabular}{|c|c|c|c|}
\hline \multirow{2}{*}{ Factors of risk - no/N (\%) } & \multirow{2}{*}{ Default $(N=64)$} & \multicolumn{2}{|c|}{ Classical PH Cox model } \\
\hline & & HR [95\%Cl] & P-value \\
\hline Unknown & $2(0.16)$ & $2.37[0.54 .10 .43]$ & 0.2533 \\
\hline
\end{tabular}

Regimen

$\begin{array}{lclc}\text { ERHZR } & 53(4.32) & \text { Reference group } & \\ \text { SERHZ } & 10(0.82) & 0.26[0.06 ; 1.17] & 0.079 \\ \text { RHZ } & 1(0.08) & 3.21[0.17 ; 62.74] & 0.4414\end{array}$

Unit of DOTS

$\begin{array}{llll}\text { Cotonou } & 37(3.02) & \text { Reference group } & \\ \text { Porto-Novo/Akron } & 21(1.71) & 1.10[0.63 ; 1.90] & 0.7422 \\ \text { Other } & 6(0.49) & 0.51[0.21 ; 1.21] & 0.1259\end{array}$

Table 6 Cox Regression PH assumptions

\begin{tabular}{|c|c|c|c|c|}
\hline \multirow[b]{2}{*}{ Time dependent co-variables } & & \multirow[b]{2}{*}{ Classical PH Cox model HR $[95 \% \mathrm{Cl}]$} & \multicolumn{2}{|c|}{ Linearity assumption } \\
\hline & & & $\begin{array}{l}\text { Wald Chi- } \\
\text { Square }\end{array}$ & P-value \\
\hline \multicolumn{5}{|l|}{ (Age group) $^{*} \log ($ default time $)$} \\
\hline & $0-14) /(15-64)$ & $1.21[0.21 ; 6.36]$ & 0.03 & 0.8712 \\
\hline & $65+/(15-64)$ & 0 & 0 & 0.9812 \\
\hline \multicolumn{5}{|l|}{ (HIVIAIDS)* log(default time) } \\
\hline & HIV+/HIV- & I.2I $[0.53 ; 2.74]$ & 0.21 & 0.6491 \\
\hline & Other/HIV- & $3.93[0.39 ; 38.79]$ & 1.37 & 0.2417 \\
\hline (TB History)* log(default time) & Other/New & $0.97[0.36 ; 2.64]$ & 0 & 0.952 \\
\hline
\end{tabular}

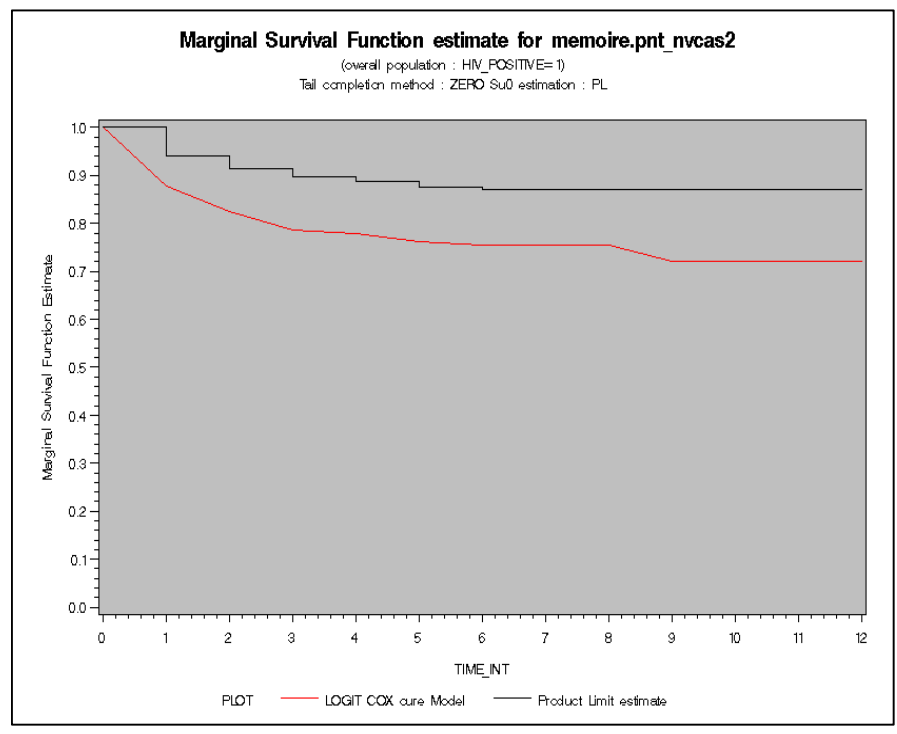

Figure 3 Default time curves using the KME and the Mixture cure model.

\section{Effect of covariates using the mixture cure}

Data was designed such that each of the selected covariates has an effect on both the cured fraction and the survival of the uncured individuals or patients who experienced a default. The Use of the standard Cox PH model is linked to the hypothesis that, if complete follow-up were possible for all patients, each would have eventually experienced the default from treatment. This hypothesis, however, did not hold for the dataset at hand. Some individuals were cured or immune against the event, resulting in the fact that default time distribution was improper as it has total mass less than 1. Indeed, from the figure 3, the KME curve levels off at nonzero proportion (around $88 \%$ ) at the right tail and exhibits a relatively long and stable plateau (Figure 3). Combined with the fact that the last default time was censored, this supported the applicability of the mixture cure model. ${ }^{57,61}$ Another evidence of the presence of immune individuals in the 2008 cohort of TB patients was based on the value of the largest event time. ${ }^{61}$ The largest default time was censored. This led to the rejection of the hypothesis of no immune patient in the source population of the cohort which establishing the evidence of sufficient follow-up. Added to this, we found $5.22 \%$ of default, satisfying the cut-off criterion of at least $5 \%$ of event needed to apply the mixture cure model..$^{57}$

All the Cox PH mixture cure models showed that the selected covariates had no effects on the default time of the uncured individuals. The HR and 95\%CI for the logistic Cox's PH mixture cure model were $(1.05[0.63 ; 1.75], \mathrm{P}=0.848)$ for HIV/AIDS-positive, $(0.86[0.30 ; 2.45], \mathrm{P}=0.782)$ for age and $(1.06[0.26 ; 4.43], \mathrm{P}=0.934$ for TB history respectively, with the $95 \% \mathrm{CI}$ of all the HR containing 
1 (table 7, survival component). On the other hand, the logistic component suggested that those covariates significantly predicted default from treatment for the cured patients (Odds ratios (OR) and [95\% $\mathrm{CI}]$ were $(4.04$ [2.64; 7,08], $\mathrm{P}<0.0001)$ for HIV/AIDS-positive, (4.23 $[1.58 ; 12.10], \mathrm{P}=0.006)$ for 65 years old or more, and $(0.04[0.00$; $0.54], \mathrm{P}=0.015$ ) for previous $\mathrm{TB}$ infection respectively, with the $95 \% \mathrm{CI}$ not including 1 as the Incidence model indicated (Table 7). Alike the cured fraction of the logistic Cox's PH mixture cure model, both the PH Cox Log-logistic and the PH Cox weibull cure models concluded that the selected covariates also significantly influenced default of anti-TB treatment (Table 7, incident component).

\section{Discussion}

\section{The risk of default}

This study shows a higher proportion of default from anti-TB treatment course compared with the level found by a previous study conducted in Benin. ${ }^{9}$ This increasing in default proportion may be viewed as a limitation in TB surveillance strategy of the local NTP as it exceeded the prior level and was $2 \%$ higher than the rate recommended by WHO. ${ }^{38}$ However, it was relatively low compared with the default proportions found in the sub-Saharan African region where default rate ranged between $11.3 \%$ and $29.6 \%{ }^{62}$ Particularly in South Africa ${ }^{17}$ which has had the third highest TB incidence worldwide in $2009 .^{20}$

Concerning the intensity of default, approximately 3 out 100 patients at risk had their treatment interrupted within the first 2 months. That is a hazard rate of 0.015 per month. The important of focusing on the first 2 months is that the intensive phase of anti-TB treatment lasts 3 to 4 months accounting for the TB history of patients. In addition, a full comply with treatment is compulsory during this phase to prevent the development of drug resistance. Thus, default is not an affordable outcome for patients and NTPs. Nevertheless, default is common, even in that phase of the treatment course. A study from Maharashtra, India reported $64 \%$ of default in the intensive phase ${ }^{51}$ and another one from Zambia claimed a default rate of $29.8 \%$ occurring in the same treatment phase. ${ }^{63}$ A research from Tashkent, Uzbekistan, has reported that patients defaulted mostly during the intensive phase. ${ }^{64}$ Accordingly, the hazard function found in the current study supports the hypothesis that TB patients mainly interrupt anti-TB treatment early during the treatment course.$^{45}$ However, other studies from Benin NTP and elsewhere have issued higher proportions of default during the continuation phase of the treatment. $^{8}$

Table 7 Factors predicting default time using the mixture cure models, and fit statistics

\begin{tabular}{lllll}
\hline & Classical PH Cox & $\begin{array}{l}\text { Logistic PH Cox Mixture } \\
\text { Cure }\end{array}$ & $\begin{array}{l}\text { Log logistic PH Cox } \\
\text { Mixture Cure }\end{array}$ & $\begin{array}{l}\text { Weibull PH Cox Mixture } \\
\text { Cure }\end{array}$ \\
\hline Incidence Component & OR $[95 \% \mathrm{Cl}]$ & OR $[95 \% \mathrm{Cl}]$ & OR $[95 \% \mathrm{Cl}]$ & OR $[95 \% \mathrm{Cl}]$ \\
HIV+ & Not applicable & $4.04[2.64 ; 7.08]$ & $4.10[2.39 ; 7.02]$ & $4.07[2.36 ; 6.96]$ \\
Age $(65+)$ & Not applicable & $4.23[1.58 ; 12.10]$ & $3.92[1.26 ; 12.25]$ & $4.05[1.27 ; 12.93]$ \\
TB History (New) & Not applicable & $0.04[0.00 ; 0.54]$ & $0.03[0.00 ; 0.76]$ & $0.04[0.00 ; 0.66]$ \\
Regimen SERHZ) & Not applicable & $0.09[0.01 ; 1.20]$ & $0.06[0.00 ; 2.43]$ & $0.08[0.00 ; 1.54]$ \\
Unit (DOTS) & Not applicable & $0.64[0.31 ; 1.32]$ & $0.50[0.21 ; 1.21]$ & $0.63[0.20 ; 2.00]$ \\
Survival component & HR $[95 \% \mathrm{Cl}]$ & $\mathrm{HR}[95 \% \mathrm{Cl}]$ & $\mathrm{HR}[95 \% \mathrm{Cl}]$ & $\mathrm{HR}[95 \% \mathrm{CI}]$ \\
HIV+ & $3.97[2.32 ; 6.79]$ & $1.05[0.63 ; 1.75]$ & $0.96[0.36 ; 2.53]$ & $0.95[0.52 ; 1.74]$ \\
Age $(65+)$ & $3.45[1.22 ; 9.72]$ & $0.86[0.30 ; 2.45]$ & $0.96[0.13 ; 7.24]$ & $0.74[0.18 ; 2.98]$ \\
TB History $(\mathrm{New})$ & $0.41[0.22 ; 0.78]$ & $1.06[0.26 ; 4.43]$ & $2.67[0.05 ; 13.30]$ & $2.00[0.23 ; 16.86]$ \\
Regimen SERHZ) & $0.26[0.06 ; 1.17]$ & $1.24[0.27 ; 5.72]$ & $2.99[0.05 ; 17.5 \mathrm{I}]$ & $2.00[0.22 ; 18.27]$ \\
Unit (DOTS) & $0.51[0.21 ; 1.21]$ & $0.45[0.18 ; 1.33]$ & $0.47[0.08 ; 2.95]$ & $0.28[0.05 ; 1.59]$ \\
\hline
\end{tabular}

Table 8 Models' goodness - of - fit

\begin{tabular}{lllll}
\hline Fit statistics & Classical PH Cox & $\begin{array}{l}\text { Logistic PH Cox Mixture } \\
\text { Cure }\end{array}$ & $\begin{array}{l}\text { Log logistic PH Cox } \\
\text { Mixture Cure }\end{array}$ & $\begin{array}{l}\text { Weibull PH Cox Mixture } \\
\text { Cure }\end{array}$ \\
\hline-2 LogL & 855.3 & 498.29 & 576.6 & 615.5 \\
AIC & 873.3 & 561.01 & 602.6 & 687.5 \\
AICC & 857.1 & 543.49 & 602.9 & 687.8 \\
BIC & 892.73 & 515.04 & 669.1 & 753.9
\end{tabular}

Amongst all the models, the logistic Cox PH cure model has best fitted data as it yielded the lowest goodness of fits criteria (Table 8). 
This wide range of default times may reflect differences in the designs of studies. Whatever the designs of studies, both quantitative and qualitative efforts must be invested to avoid any default during this period as default could be the most important predictor of MDR-TB. ${ }^{12,65}$ MDR-TB is resistant to both isoniazid and rifampicin with or without resistance to other drugs. ${ }^{12}$ This indicates that much health education still need to be done although Benin is one of the leading countries in applying and achieving international targets in the control of TB. ${ }^{66}$

\section{Effect of covariates}

The logistic Cox PH mixture cure model reveals that the timing of default from anti-TB treatment was not important to learn the risk pattern of treatment interruption. Rather, default was the target dependent variable to model. This may be plausible as the cured fraction was high $(94.1 \%)$, meaning that more than $94 \%$ of the patients have fully complied with treatment course. This supports an underlying assumption of cure model which assumes heavy proportion of censoring or cured fraction at the right tail of follow up. ${ }^{56}$ As a matter of fact, a simple binary model may be appropriate to analyze the risk of default for those patients. ${ }^{56}$ Hence, logistic regression with adjusted OR would have been relevant for the current study. However, severe warnings raised concerns about the convergence criterion. This was generated from the simulation algorithm used for the numerical computations of the estimates. The model fit validity, therefore, is questionable. On the other hand, the results of the Cox regression were consistent with the proportional hazards assumption. Thus, rather than default from anti-TB treatment itself, its timing is the target variable to address. Consequently and for the time being, we have preferred the classical Cox $\mathrm{PH}$ regression even though it has underestimated the hazard function of the default time as the corresponding curve is higher compared with the estimated curve given by the mixture cure model (Figure3).

With the classical Cox PH model, HIV/AIDS-positive, TB history and Age were the significant predictors of default time from anti-TB treatment. The posterior probability of being uncured was $5.99 \%$ which was approximately the same as its prior probability $(5.22 \%)$. Put together, these facts are probably a guaranty of the accuracy of our study.

\section{The risk pattern}

HIV/AIDS: A patient with HIV/AIDS-positive has a higher risk to show severe $\mathrm{TB}^{67,68}$ and he will default from anti-TB treatment about 4 times more than a patient with HIV/AIDS-negative. In Benin, the upper limit of the rate of co-infection with HIV/AIDS was $18.5 \%$, or almost one fifth of total TB patients. This could confirm the fact that TB is the most common opportunistic disease and the most common cause of burden in patients with HIV/AIDS infection in developing countries. ${ }^{67,68}$ But the mechanism by which the co-infection induces default from anti-TB treatment remains unclear. In Benin, the province of Atlantique-Littoral has a high risk of co-infection..$^{48}$ Evidence has shown that the concomitant treatment causes severe side effects ${ }^{68}$ leading, probably, to premature drop from anti-TB treatment. To avoid this, an optimal timing in starting the co-treatment ${ }^{68}$ could prevent the immunological weaken in patients with concurrent HIV/AIDS. Thus, Untreated HIV infection may reduce the number of $\mathrm{CD} 4+\mathrm{T}$ lymphocytes as $\mathrm{CD} 4+$ cells play a major role in the body's defense against tubercle. ${ }^{67}$ Therefore we think that patients with high TB/HVI concomitant burden could be tempted to leave treatment prematurely and for these reasons TB and HIV programs integration need to be continually optimized. ${ }^{68}$
TB history: The risk of default was greater for new TB patients than for patients with previous TB infection. This study indicated that incident TB patients were $87 \%$ at high risk of defaulting from the anti-TB treatment course before its end. A study from Russia showed that among new TB patients, $63 \%$ of defaulters have interrupted treatment during the intensive phase. ${ }^{69}$ In India $41 \%$ of defaulters were new TB patients representing $12 \%$ of patients who have interrupted treatment within the first 2 months. This falls to $11.3 \%$ from a study conducted in Ethiopia. ${ }^{63}$

AGE: Patients who were 65 years old or more were 3.5 times more likely to interrupt the anti-TB treatment than patients whose age was between 15 and 64 years old, suggesting that elder patients were at greater risk than the others. This could be plausible as, this category of patients request more social support from their communities. In addition, the duration of treatment, which is 6 to 8 months, is long in terms of separation from patients' home towns and daily habits. Therefore, programs of DOTS at home or inside the community of origin could be a better TB surveillance strategy for the elder TB patients.

\section{Added values of this study}

In the context of Benin, this study tried an innovation as the previous comparable study conducted in the country only had partially tackled interruption of treatment without having addressed its timing. ${ }^{9}$ We determined the hazard rate of default and attempted to explain both the related predictive factors and the cured fraction of the 2008 TB cohort. To achieve this we applied conjointly Cox regression and cure models for an in-depth understanding of the risk pattern of default from anti-TB treatment and its timing. However the estimates from the cure model could have been biased due to concerns about the computational algorithm. Yet, the findings may be important, beyond the case of Benin, to countries with similar TB epidemiology profile, such as many countries in Sub-Saharan Africa, Asia and part Eastern Europe.

\section{Limitations of this study}

Several methodological issues should be discussed. Firstly, results of this study come from Southern Benin and may not completely represent the conditions in the whole country even though the sample used was 33\% (1226/3741) of the total 2008 TB patient's cohort. Therefore we need to apply our model on a test set for the external validity purposes. Secondly, the algorithms used to implement the mixture cure model did not converge for several iterations, resulting in some difficulties in computing the related likelihood estimators. This could have been caused by several computational problems such as the high rate of ties in data and the fact that the true proportion of default $(5.22 \%)$ was border line. Despite the fact that the underlying hypotheses and theoretical conditions were met, an improvement is necessary. Finally, some underlying potential predictive factors essential to adjust the hazard of defaulting from anti-TB treatment are missing. The socioeconomic and educational status of the patients, ARV, CTM and known competing diseases could highly improve the modeling.

\section{Conclusion}

The results from this study showed that in the south of Benin at whole, TB patients mostly defaulted from anti-TB therapy at the beginning of the treatment course with a related relatively low risk. Added to this finding was that not all the patients were susceptible to default. In this way, the combination of the classical survival 
analysis and the mixture cure model was useful. However, it was challenging to know who was not susceptible and vice versa before the end of the follow up. Therefore it is important to consider early the HIV/AIDS status and the age of patients as well as their TB history as underlying factors for compliance with anti-TB treatment in future. Of course, further investigations are needed about the timing of default from anti-TB treatment in Benin. For instance, prospective research integrating the impact of the malnutrition, patients' immunological state and the genomics of TB may be interesting.

\section{Acknowledgement}

None.

\section{Conflict of Interest}

The authors declare that they have no financial or non-financial competing interests.

\section{References}

1. Maartens G, Wilkinson RJ. Tuberculosis. Lancet. 2007;370(9604):20302043.

2. Corbett EL, Watt CJ, Walker N, et al. The growing burden of tuberculosis: global trends and interactions with the HIV epidemic. Arch Intern Med. 2003;163(9):1009-1021.

3. Murray CJL, Lopez AD. Global mortality, disability, and the contribution of risk factors: Global Burden of Disease Study. The Lancet. 1997;349(9063):1436-1442.

4. WHO. Global Tuberculosis Control: A Short Update to the 2009 Report 2009.

5. WHO. Tuberculosis, Fact sheet. Fact Sheet No. 104. 2010.

6. WHO. Tuberculosis country profiles. 2009.

7. WHO. Global Tuberculosis Control: Surveillance, Planning and Financing. 362. 2006.

8. République du Bénin Ministère de la Santé DNPS. Programme National contre la Tuberculose: Rapport annuel. 2008.

9. Akpamoli A KL. Evaluation de l'impact sanitaire du passage à l'échelle des interventions de lutte contre le SIDA, la tuberculose et le paludisme, avec l'appui du Fonds Mondial. 2009.

10. Dye $\mathrm{C}$, Maher $\mathrm{D}$, Weil $\mathrm{D}$, et al. Targets for global tuberculosis control. Int J Tuberc Lung Dis. 2006;10(4): 460-462.

11. Borgdorff MW, Floyd K, Broekmans JF. Interventions toreduce tuberculosis mortality and transmission in low- and middle-income countries. Bull World Health Organ. 2002;80(3):217-227.

12. Sharma SK, Mohan A. Multidrug-resistant tuberculosis - A menace that threatens to destabilize tuberculosis control. Chest. 2006;130(1):261272.

13. Fogarty International Center of the US National Institutes of Health, The World Bank, WHO/PRB. Tuberculosis Is the Principal Cause of Death From a Curable Infectious Disease, But Treatment is Highly Cost Effective. Disease Contol Prioties project . 2006.

14. Rabahi MF, Rodrigues AB, Queiroz de Mello F, et al. Noncompliance with tuberculosis treatment by patients at a tuberculosis and AIDS reference hospital in midwestern Brazil. Braz J Infect Dis. 2002;6(2):63-73.

15. Squire SB, Wilkinson D. Strengthening "DOTS" through community care for tuberculosis. BMJ. 1997;315(7120):1395-1396.
16. Jaiswal A, Singh V, Ogden JA, et al. Adherence to tuberculosis treatment: lessons from the urban setting of Delhi, India. Trop Med Int Health. 2003;8(7):625-633.

17. Connolly C, Davies GR, Wilkinson D. Who fails to complete tuberculosis treatment? Temporaltrends and risk factors for treatment interruption in a community-based directly observed therapy programme in a rural district of South Africa. Int J Tuberc Lung Dis. 1999;3(12):1081-1087.

18. Diwan VK, Thorson A. Sex, gender, and tuberculosis. Lancet. 1999,353(9157):1000-1001.

19. Thomas C. A literature review of the problems of delayed presentation for treatment and non-completion of treatment for tuberculosis in less developed countries and ways of addressing these problems using particular implementations of the DOTS strategy. $J$ Manag Med. 2002;16(4-5): 371-400.

20. World Health Organization. Global Tuberculosis Control 2010. WHO Library Cataloguing-in- Publication Data. .

21. Cuneo WD, Snider DE. Enhancing Patient Compliance with Tuberculosis Therapy. Clin Chest Med. 1989;10(3):375-380.

22. $\mathrm{Xu} \mathrm{W}, \mathrm{Lu} \mathrm{W}, \mathrm{Zhou} \mathrm{Y}$, et al. Adherence to anti-tuberculosis treatment among pulmonary tuberculosis patients: a qualitative and quantitative study. BMC Health Serv Res. 2009;9:169.

23. Jakubowiak W,Bogorodskaya E, Borisov S, et al. Treatment interruptions and duration associatedwith default among new patients with tuberculosis in six regions of Russia. Int J Infect Dis. 2009;13(3):362-368.

24. Amoran OE, Osiyale OO, Lawal KM. Pattern of default among tuberculosis patients on directlyobserved therapy in rural primary health care centres in Ogun State, Nigeria. Journal of Infectious Diseases and Immunity. 2011;3(5):90-95.

25. Shargie EB, Lindtjørn B. Determinants of treatment adherence among smear-positive pulmonary tuberculosis patients in Southern Ethiopia. PloS Med. 2007;4(2):e37.

26. Addington WW. Patient Compliance - Most Serious Remaining Problem in the Control of Tuberculosis in the United-States. Chest. 1979;76(S6):741-743.

27. Burkhart PV, Sabate E. Adherence to long-term therapies: Evidence for action. J Nurs Scholarsh. 2003;35(3):207.

28. Comolet TM, Rakotomalala R, Rajaonarioa H. Factors determining compliance with tuberculosis treatment in an urban environment, Tamatave, Madagascar. Int J Tuberc Lung Dis. 1998;2(11):891-897.

29. Farmer P. Social scientists and the new tuberculosis. Soc Sci Med. 1997;44(3):347-358.

30. Fox W. Compliance of Patients and Physicians - Experience and Lessons from Tuberculosis -II. Br Med J (Clin Res Ed). 1983;287(6385):101-105.

31. Picon PD, Assanesi SL, Caramori ML. Risk factors for recurrence of tuberculosis. J Bras Pneumol. 2007;33(5):572-578.

32. Sumartojo E. When tuberculosis treatment fails. A social behavioral account of patient adherence. Am Rev Respir Dis. 1993;147(5):13111320.

33. Tangüis HG1, Caylà JA, García de Olalla PG, et al. Factors predicting noncompletion of tuberculosis treatment among HIV-infected patients in Barcelona (1987-1996). Int J Tuberc Lung Dis. 2000;4(1):55-60.

34. Thomas C. A literature review of the problems of delayed presentation for treatment and non-completion of treatment for tuberculosis in less developed countries and ways of addressing these problems using particular implementations of the DOTS strategy. J Manag Med. 2002;16(4-5):371-400 
35. Sagbakken M, Frich JC, Bjune G.Barriers and enablers in the management of tuberculosis treatment in Addis Ababa, Ethiopia: a qualitative study. BMC Public Health. 2008;8:11.

36. Baiden F, Remes P, Baiden R, et al. Voluntary counseling and HIV testing for pregnant women in theKassena-Nankana district of northern Ghana: is couple counseling the way forward? AIDS Care. 2005;17(5):648-657.

37. Who. Treatment of tuberculosis: guidelines for national programmes. Third Edition. Geneva. 2003.

38. Romanus V, Julander I, Blom-Bülow B, et al. Shortages in Swedish tuberculosis care. Good results only in 71 percent of cases after 12-month treatment as shown in a current study. Lakartidningen. $2000 ; 97(48): 5613-5616$.

39. Jha UM, Satyanarayana S, Dewan PK, et al. Risk Factors for Treatment Default among Re-Treatment Tuberculosis Patients in India, 2006. Plos One. 2010;5(1):e8873.

40. Kolappan C, Subramani R, Kumaraswami V, Santha T, Narayanan PR (2008) Excess mortality and risk factors for mortality among a cohort of TB patients from rural south India. Int J Tuberc Lung Dis 12(1): 81-86.

41. Glantz SA. Primer of Biostatistics: Sixth Edition. 6th Edition, 500 Pages. 2005. McGraw-Hill. 2005

42. Klein JP, Moeschberger ML. Survival analysis: Techniques For Censored and Truncated Data. Second Edition, 235 Pages[Statistics for Biology and Health]. New York, Springer-Verlag. 2003.

43. Kruk ME, Schwalbe NR, Aguiar CA. Timing of default from tuberculosis treatment: a systematic review. Trop Med Int Health. 2008;13(5):703-712.

44. Breen RA, Miller RF, Gorsuch T, et al. Adverse events and treatment interruption in tuberculosis patients with and without HIV co-infection. Thorax. 2006;61(9):791-794.

45. The World Medical Association. A Tuberculosis Refresher Course for Physicians.2007.

46. Juzar A. The Many Faces of Tuberculosis Control and the Challenges Faced. Respiratory Care. 2005;1-4. 2005.

47. République du Bénin Ministère de la Santé DNPS. Programme National contre la Tuberculose: Rapport annuel. 2008

48. UNFPA PRB. World Population data Sheet. 2008.

49. Garner P, Smith H, Munro S, et al. Promoting adherence to tuberculosis treatment. Bull World Health Organ. 2007;85(5):404-406.

50. Corbière F, Joly P. A SAS macro for parametric and semiparametric mixture cure models. Comput Methods Programs Biomed. 2007;85(2):173180

51. Allison PD. Survival Analysis Using SAS: A Practical Guide. Cary, NC: SAS Institute Inc. SAS Institute Inc., Cary, NC, USA;1995.
52. Gharibvand L, Fernandez G. Survival Analysis Plots Using SAS Æ ODS Graphics. Reno. 2011.

53. Nguyen PT, Henrard S, Coche E, et al. Coronary artery calcification: a strong predictor of cardiovascular events in renal transplant recipients. Nephrol Dial Transplant. 2010;25(11):3773-3778.

54. Kuk AYC, Chen C-H. A mixture model combining logistic regression with proportionalhazards regression. Biometrika. 1992;79(3):531-541.

55. Corbière F, Joly P. A SAS macro for parametric and semiparametric mixture cure models. Comput Methods Programs Biomed. 2007;85(2):173180 .

56. Farewell VT. The Use of Mixhwe Models for the Analysis of Sureval Data with Long-Term Survivors. Biometrics. 1982;38:1041-1046.

57. McLachlan GJ, Chrishnan T. The EM Algorithm and Extensions. Second Edition ed. WILEY- INTERSCIENCE; 1996.

58. International Epidemiolocal Association. GOOD EPIDEMIOLOGICAL PRACTICE (GEP): IEA GUIDELINES FOR PROPER CONDUCT IN EPIDEMIOLOGIC RESEARCH.

59. Maller RA, Zhou X. Survival analysis with long-term survivors. [Testing for sufficient follow-up in survival data]. 1996. John Wiley \& Sons, Ltd., Chichester; 1996.

60. Castelnuovo B. A review of compliance to anti tuberculosis treatment and risk factors for defaulting treatment in Sub Saharan Africa. Afr Health Sci. 2010;10:320-324.

61. Kruk ME, Schwalbe NR, Aguiar CA. Timing of default from tuberculosis treatment: a systematic review. Trop Med Int Health. 2008;13(5):703-712.

62. Hasker E, Khodjikhanov M, Usarova S, Asamidinov U, Yuldashova U, et al. Default from tuberculosis treatment in Tashkent, Uzbekistan; Who are these defaulters and why do they default?. BMC Infect Dis. 2008;8:97.

63. Mitchison DA. How drug resistance emerges as a result of poor compliance during short course chemotherapy for tuberculosis. Int $J$ Tuberc Lung Dis. 1998;2(1):10-15.

64. WHO Global Tuberculosis Program. WHO report on the global tuberculosis epidemic 1998. Geneva: World Health Organization, 1998.

65. Dye C, Scheele S, Paul Dolin, et al. Global Burden of Tuberculosis: Estimated Incidence, Prevalence, and Mortality by Country. JAMA. 1999;282(7):677-686.

66. Abdool Karim SS, Naidoo K, Grobler A, et al. Timing of Initiation of Antiretroviral Drugs during Tuberculosis Therapy. $N$ Engl $\mathrm{J} \mathrm{Med}$. 2010;362(8):697-706.

67. Jakubowiak W, Bogorodskaya E, Borisov S, et al. Treatment interruptions and duration associatedwith default among new patients with tuberculosis in six regions of Russia. Int J Infect Dis. 2009;13(3):362-368. 